$1-31-2021$

\title{
Assessing the performance of community health workers in Haiti: Key findings from a mixed-methods study
}

Frontline Health Project

Zanmi Lasante

Follow this and additional works at: https://knowledgecommons.popcouncil.org/departments_sbsr-rh

Part of the Community Health and Preventive Medicine Commons, and the Maternal and Child Health Commons

How does access to this work benefit you? Let us know!

\section{Recommended Citation}

Frontline Health Project and Zanmi Lasante. 2021. "Assessing the performance of community health workers in Haiti: Key findings from a mixed-methods study," Results brief. Washington, DC: Population Council. 


\section{ASSESSING THE PERFORMANCE OF COMMUNITY HEALTH WORKERS IN HAITI: KEY FINDINGS FROM A MIXED-METHODS STUDY}

\section{BACKGROUND}

Two decades of successive crises in Haiti have manifested in recurring social upheavals and continuous economic insecurity. Natural disasters including earthquakes and hurricanes, political unrest and associated transitions of power, and disease outbreaks have led to civil unrest, internal displacement, gang violence, civil lockdowns, broken infrastructure, constrained supply chains, food insecurity, and poor health outcomes, all of which threaten Haiti's under-resourced health system (1).

For many Haitians, especially those in rural areas, their initial, and often only, means of contact with their health system is through community health workers (CHWs). CHWs have "up to six months of initial training, serving communities with limited access to facility-based health care. Often as community members themselves, CHWs possess an understanding of the local context, including barriers and facilitators to accessing timely and quality PHC [primary health care]" (2).

Haitian government spending on health, as a percentage of GDP, decreased over the last decade, resulting in many Haitians' inability to access or afford health care: An estimated $76 \%$ of Haitians cite treatment costs, while another $43.1 \%$ report distances to health facilities, as primary barriers to their health care (3).

Amplifying these barriers to health care is the shortage of health workers in Haiti, with 0.27 health workers for every 1,000 inhabitants, far below the World Health Organization (WHO)'s recommended 4.5 health workers per 1,000 inhabitants (4).

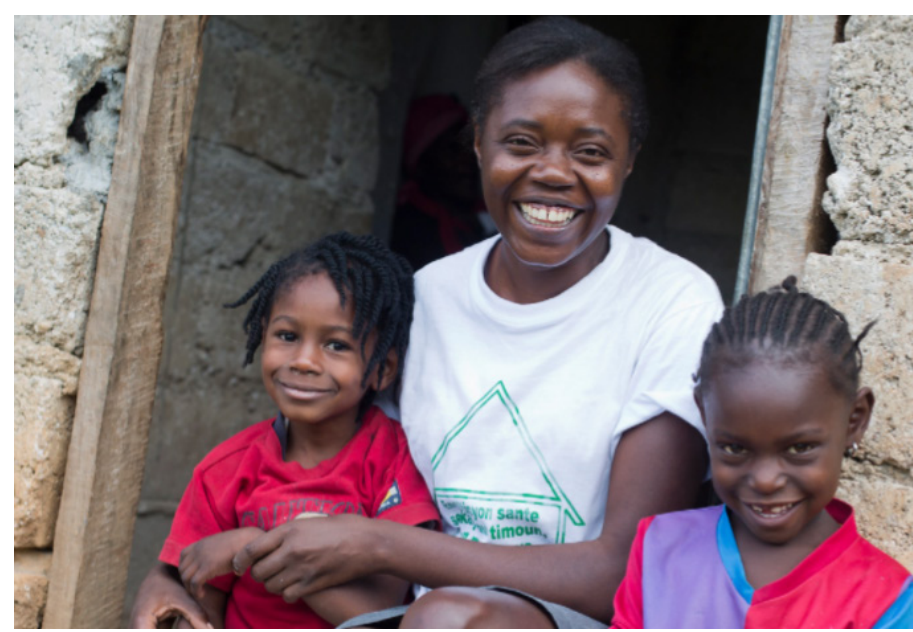

A CHW on a home visit in Haiti. Credit: USAID, 2014.

\section{KEY FINDINGS}

1. In humanitarian settings such as Haiti, CHWs act as PHC providers and critical intermediaries that link communities with the formal health system.

2. CHWs in Haiti are highly trusted and valued members of their communities, often acting in multiple roles at once.

3. Referral and counter-referral systems in Haiti should be strengthened to better serve community needs, through increased CHW training and support for more effective use of those systems.

\footnotetext{
This brief summarizes quantitative and qualitative baseline data from the Frontline Health project's study in Haiti. Baseline data collection took place between August-October 2019 in three communes: Petite Riviere de L'Artibonite (PRA) and Verrettes in the Artibonite region, and Mirebalais in the Centre region. The information presented in this brief is based on key findings from a document/policy review, a survey of referred patients ( $n=627$ ), two focus group discussions (FGDs) with referred patients, and in-depth interviews (IDIs) with CHWs ( $n=24)$, CHW supervisors and program stakeholders $(n=15)$, and policy stakeholders $(n=12)$.
} 


\section{THE ROLE OF COMMUNITY HEALTH WORKERS IN HAITI}

Haiti's CHWs are locally known as agents de santé communautaire polyvalent (ASCPs). Formally recognized in 2015 as salaried health workers by the Ministry of Public Health and Population (Ministère de la Santé Publique et de la Population, MSPP), ASCPs have different means of reaching local communities to provide clinical servicesduring periodic outreach efforts, health campaigns, and regular visits at health posts. They also provide health education through home visits in their communities, to mothers groups and during community meetings.

ASCPs are employed, trained, and equipped by the MSPP in addition to local non-governmental organizations (NGOs). ASCPs are supervised by auxiliary nurses. Within their local communities, ASCPs are part of a "family health team" or équipe de la santé famille (ESF) responsible for planning and coordinating their activities. Each ESF serves approximately 60,000 inhabitants and comprises 60 ASCPs and four supervisory auxiliary nurses (5).

ASCPs serve fellow Haitians often enduring poor educational, economic, and psychological circumstances (see Figure 1). In a primarily female sample of referred patients in Lower Artibonite and Central departments, most resided with domestic partners (93\%)-and more than $50 \%$ had never attended school, $82 \%$ had between one and six children, and over one third endured the death of a child. Many reported having no occupation in the last year and limited assets.

\footnotetext{
"People often contact their ASCPs for advice. In the meantime, ASCPs often visit people to counsel, monitor their blood pressure. As I have experienced, you see the ASCP take the money out of his pocket to get a patient to the hospital."-Women's focus group, Mirebalais
}

In addition to their formal duties, ASCPs assume informal roles in their communities - as caregivers, friends, conflict mediators, and confidantes. ASCPs make extraordinary efforts to accommodate and support their patients, at times providing services to households beyond their professionally mandated responsibilities. One ASCP described providing instrumental support for a widow's children's return to school:

\section{FIGURE 1. DEMOGRAPHIC INDICATORS OF SURVEY RESPONDENTS}

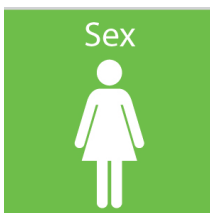

$85 \%$ female

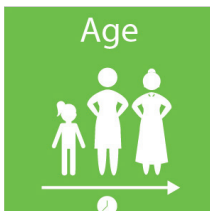

Mean age 40 years old

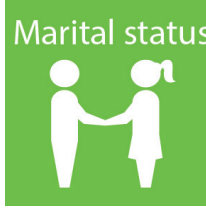

$39 \%$ married $54 \%$ unmarried and living with partner

\section{Number of \\ children \\ की}

5\%: None

49\%: 1-3

$33 \%: 4-6$

13\%: 7 or more

35\%: A child died
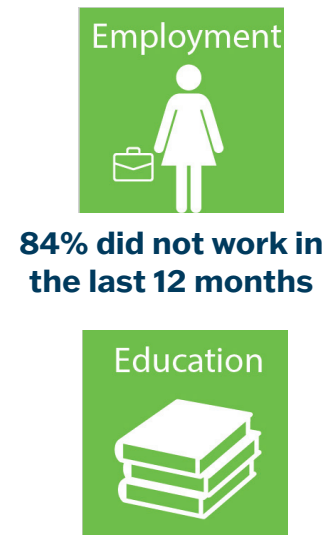

$59 \%$ never attended school

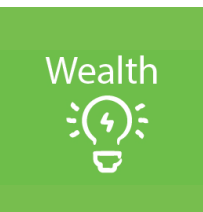

$21 \%$ households have electricity

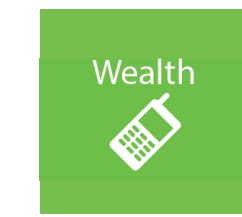

$49 \%$ households have a mobile phone

“One of my patients' husband passed away, [and] the children cannot go to school. So Friday I had to go the office to talk to a director and asked him what was needed for the children to attend school... He told me I need two report cards, two birth certificates and two photographs, all stamped... [I] not only have to make sure the patient takes her medication, but I also have to take care of her other problems."

-ASCP, Verrettes 


\section{TRUSTING RELATIONSHIPS AND REFERRALS BETWEEN ASCPS AND THEIR COMMUNITIES}

Communities, ASCPs, and ASCP supervisors alike recognize the importance of establishing trusting relationships, which allow ASCPs to be more effective. Communities report no preference for either male or female ASCPs, and have frequent interactions with ASCPs, with ASCPs spending significant time (over half an hour) during each interaction (58\%). Community respondents also report high levels of satisfaction with ASCPs' services, with more than half (56\%) indicating they would recommend their ASCP to other community members, indicating generally positive, trusting, and reinforcing relationships (Table 1).

\section{"Everyone [ASCPs] is fully appreciated. All children love them. When they give kids shots, they cry because it stings, but later they are friends again. The ASCPs near me are good people. We can trust them by telling them anything." - Women's focus group, Mirebalais}

ASCPs view community members as friends, and value their roles as confidantes and problem-solvers within their communities, often spending time getting to know their patients and their families personally.

\footnotetext{
"The importance of taking time to sit with them; engage them in small talk, if time permits, you stay 30-40 minutes. We talk about everyday life, their children, the other people living in the house. Then you go to the next patient's home and repeat the process: more conversation, small talk, warning them against not taking their medication...the importance of going to their appointments... you develop a good relationship with some patients where they trust you and you trust them."-ASCP, Verrettes
}

ASCPs, as members of the communities they serve, evince concern for their patients, and feel accomplished and encouraged when they see patient health and livelihoods improving.

\footnotetext{
"As I work, I will provide services even when they are not $100 \%$ but they improve the community and the community appreciates me too. So, no matter where I go, I will never rush because while on the road there are people calling you, asking for advice and it makes me proud."-ASCP, Petite Rivière de l'Artibonite
} TABLE 1. SELECTED RELATIONAL INDICATORS,
RESPONDENT SURVEY

\section{Indicator}

$\%(n=627)$

No preference in male or female $\mathrm{CHW}$

$55 \%$

Number of times the $\mathrm{CHW}$ visited within the last 6 months

\begin{tabular}{|c|c|}
\hline Once & $11 \%$ \\
\hline $2-5$ times & $49 \%$ \\
\hline 6 or more times & $40 \%$ \\
\hline \multicolumn{2}{|c|}{ Time CHW spent with you or your child (recent visit) } \\
\hline$<30$ minutes & $42 \%$ \\
\hline 30 min-1 hour & $45 \%$ \\
\hline 1 or more hours & $13 \%$ \\
\hline $\begin{array}{l}\text { Very satisfied with services received from } \\
\mathrm{CHW}\end{array}$ & $93 \%$ \\
\hline Would recommend a friend to see the $\mathrm{CHW}$ & $56 \%$ \\
\hline
\end{tabular}

\section{REFERRAL AND COUNTER- REFERRAL SYSTEM CHALLENGES}

ASCPs refer patients to health facilities who require care exceeding their own capacities. ASCPs direct patients with completed referral forms to either a local health center or community referral hospital. If necessary, patients are then referred to departmental hospitals (6). ASCPs, in theory, receive patient counter-referral forms from the health facilities that provided referral care, and provide follow-up care to their patients as needed.

In practice, ASCPs face numerous challenges in the referral and counter-referral process, including convincing patients to complete their referrals. Frontline Health project data reveal challenges within the referral and counter-referral processes that warrant attention. Over $90 \%$ of patients surveyed indicated that an ASCP referred them to a hospital, yet only $45 \%$ of referred patients completed those referrals.

Of those who completed their referrals ( $n=275), 72 \%$ lived within one hour's travel to a facility and $77 \%$ took public transportation, but only $39 \%$ had health insurance for facility-based care and $20 \%$ experienced a problem with their services at a health care facility (Table 2 ).

Out of the 63 patients who provided a reason for not completing a referral for care (341 total non-completions), $27 \%$ had experienced prior mistreatment (e.g. treated in an unfriendly or unprofessional manner by referral providers) at the referral facility, for $29 \%$ the facility was too distant, with travel either too expensive or unavailable, and an additional $29 \%$ reported other reasons for noncompletion. ASCPs concur that cost and distances to 
TABLE 2. SELECT REFERRAL INDICATORS

\begin{tabular}{|c|c|}
\hline Indicator & $\%(n=627)$ \\
\hline ASCP referred to a hospital & $90 \%$ \\
\hline Completed referral made by ASCP & $45 \%$ \\
\hline Out of those who completed referrals & $\%(n=275)$ \\
\hline Did you go to where you were referred? & $83 \%$ \\
\hline Had health insurance to go to facility? & $39 \%$ \\
\hline \multicolumn{2}{|l|}{ Length of time took to get to facility } \\
\hline Less than $30 \mathrm{~min}$ & $38 \%$ \\
\hline 30 min to 1 hour & $34 \%$ \\
\hline $1-2$ hours & $14 \%$ \\
\hline More than 2 hours & $14 \%$ \\
\hline Took public transporation & $77 \%$ \\
\hline Satisfied with facility services & $81 \%$ \\
\hline $\begin{array}{l}\text { Experienced a problem with services received } \\
\text { at facility }\end{array}$ & $20 \%$ \\
\hline $\begin{array}{l}\text { Believes it's necessary to go to a facility when } \\
\text { referred by ASCP }\end{array}$ & $86 \%$ \\
\hline $\begin{array}{l}\text { Out of those who did NOT complete } \\
\text { referrals }\end{array}$ & $\%(n=341)$ \\
\hline \multicolumn{2}{|l|}{ Length of time it would take to get to facility } \\
\hline Less than $30 \mathrm{~min}$ & $21 \%$ \\
\hline 30 min to 1 hour & $17 \%$ \\
\hline $1-2$ hours & $15 \%$ \\
\hline More than 2 hours & $41 \%$ \\
\hline Do not know/unsure & $6 \%$ \\
\hline Would have gone by walking & $43 \%$ \\
\hline Would have gone by public transport or taxi & $48 \%$ \\
\hline
\end{tabular}

facilities are common barriers, and some patients who do make it to health centers for referrals report a variety of issues within the referral and counter-referral system. The quote below from an ASCP supervisor reflects the adverse experiences ASCPs and patients sometimes face with referrals and counter-referrals.

\footnotetext{
"The patients sometimes feel humiliated when they show with the referral form, staff would tell them: 'What is this thing that an ASCP referred you? I don't know them.' The patient would return with the referral form, dejected, and this sometimes causes the ASCP to say: ‘Don't ask me to do referrals, I won't do it again'. I would then tell them to continue referring patients to the hospital no matter how they are treated, and the ASCP usually listens."-ASCP Supervisor, Mirebalais
}

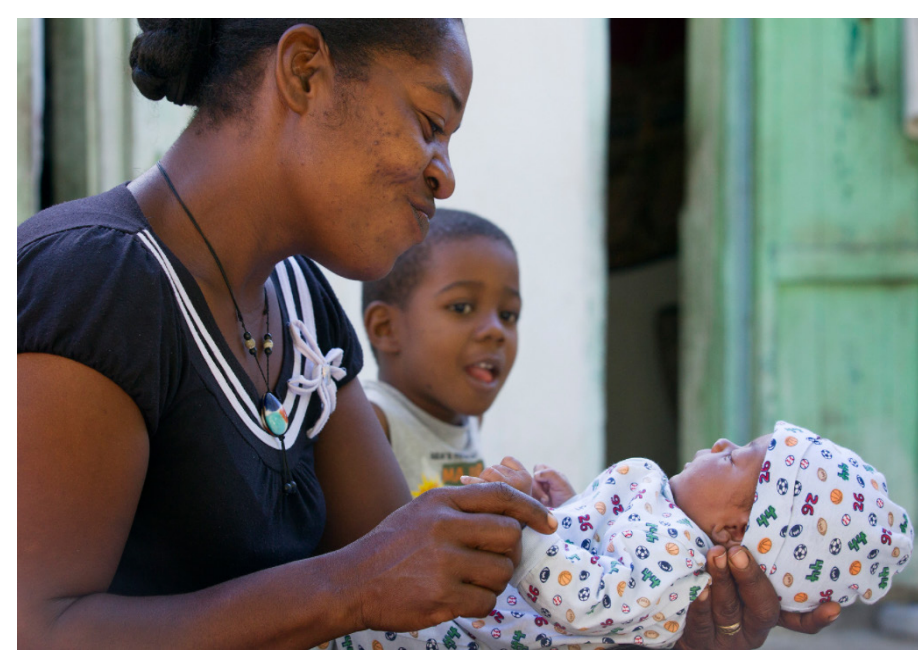

A CHW conducts a newborn check-up in Haiti. Credit: Mike DuBose, UMNS, 2013.

\section{IMPLICATIONS AND NEXT STEPS}

This brief indicates that Haiti's ASCPs are highly valued and trusted as direct health service providers in addition to referring patients to facilities for specialized care. ASCPs are particularly critical in protracted humanitarian settings such as Haiti where populations have limited access to education, jobs, and secure livelihoods.

While committed to working in their communities and linking individuals with necessary facility-based care, ASCPs and communities alike experience challenges in completing referrals, due in part to a lack of focus on guideline implementation, referral mechanisms, and supporting environments for an effective referral and counter-referral process. To address challenges with referral and counter-referral in Haiti and contribute to the limited global evidence on $\mathrm{CHW}$ referral (7), the Population Council is partnering with Zanmi Lasante (in collaboration with MSPP) to assess a referral strengthening intervention's efficacy for referral measurement, process, and completion.

Building on the ongoing referral systems in Haiti led by Zanmi Lasante, the study's intervention provides ASCPs with a one-time training, using a referral-strengthening tool (designed in collaboration the MSPP) for ensuring and tracking patient referrals. ASCPs also participate in recurring monthly meetings for review and further coaching. Implementation of the intervention began in January 2020, with some adjustments due to COVID-19. A forthcoming endline evaluation will describe trends in aggregate referrals and referral completion over time and document implementation processes, challenges, and successes from the perspectives of intervention stakeholders. 


\section{CONTACT}

\section{Alain Casseus}

Project Manager

Zanmi Lasante

acasseus@pih.org

\section{Pooja Sripad}

Technical Advisor

Population Council

psripad@popcouncil.org

\section{REFERENCES}

1. Sripad P, Casseus A, Kennedy S, Isaac B, Vissieres K, Ternier R. "Eternally restarting" or "a branch line of continuity": Exploring consequences of political transitions, natural disasters, and disease outbreak shocks on community health systems in Haiti. J Glob Health; accepted.

2. Agarwal S, Sripad P, Johnson C, Kirk K, Bellows B, Ana J...CE Warren. A conceptual framework for measuring community health workforce performance within primary health care systems. Hum Resour Health. 2019;17(1):1-20.

3. World Bank. 2017. Better Spending, Better Care: A Look at Haiti's Health Financing.

4. The World Health Organization. 2016. Health Workforce Requirements for Universal Health Coverage and the Sustainable Development Goals.

5. Frontline Health Project. 2020. "The Community Health System in Haiti: Overview." Washington, D.C.: Population Council.

6. Maternal and Child Survival Program. 2018. Establishing Model Referral Networks in Haiti: MCSP Case Study.

7. Lal S, Ndyomugenyi R, Paintain L, Alexander, ND, Hansen KS, Magnussen P, Clarke SE. (2016). Community health workers adherence to referral guidelines: evidence from studies introducing RDTs in two malaria transmission settings in Uganda. Malaria Journal. https:// doi.org/10.1186/s12936-016-1609-

Suggested citation: Frontline Health Project and Zanmi Lasante. 2021. Assessing the Performance of Community Health Workers (CHWs) in Haiti: Key Findings from a Mixedmethods Study. Washington, D.C.: Population Council. 